Spain 1976

When we arrived in Madrid everyone had gone to the bullfight, including the professor who was surgeon to the bullfighters and carried out his repairs in a small, well appointed operating theatre at the back of the ring, flanked by a fine bust of Pasteur. It was the second week in May, the Feast of San Isidro. "In this week," declaimed an excitable Spaniard on my right, "you will see in Madrid the best matadors and the best bulls in all Spain. You must always watch the most courageous matadors fight the most courageous bulls." To experience such a spectacle, says Hemingway, is to understand Spain. To see a second rate bullfight, as we did elsewhere, is to witness cruelty and depravity.

Our host came from the plains of Castile, from a poor family. "With these hands," he said, like a sad, proud matador, "I have made myself what I am." Sipping a glass of heavy Spanish sherry, we walked down to the rose garden, which was dimly lit and surrounded by a high wall. We wandered round smelling the delicious scent of the roses, which were all of one variety, bred by our host and named after him. On our return we discovered that they are grown in this country.
The appellation "professor" in Europe is given to any academic that is, one who publicly professes his own knowledge. The most all embracing title might be that of the famous painting by Holbein inc the Royal College of Surgeons in London-"The Masters," which depicts the barber surgeons being granted their charter by Henry $\overline{\overline{5}}$ VIII. By the same token, "Madame" to a married woman steers] clear of all the pitfalls of address. My husband has found ae watertight method of overcoming language difficulties with foreign $\Pi$ ladies. He stands murmuring "Madame" in tones of under-standing, commiseration, or surprise, as the speaker's demeanour $\overrightarrow{\vec{s}}$ suggests, on the premise, which every medical practitioner knows, that all that people really want is to be listened to.

Travel is an emotive affair: objects, words, concepts that have $\frac{\overline{\bar{D}}}{\overline{\mathrm{n}}}$ become too well known are in danger of passing unnoticed; but go $\vec{\sigma}$ away for a few days to another country, with other customs, and $\varrho$ what is familiar at home is seen in a fresh light. Perhaps it is worth looking again at our own familiar world of the healing arts. To us is $\overrightarrow{0}$ given the privilege-given to no other-to pass without let orhindrance through doors and across frontiers, not least into the $\vec{\omega}$ human condition. Death and illness, like sauna baths, are great $\frac{}{\circ}$ levellers, and so, too, in every country, the sun rises in the morning.

\title{
In a small boat round the world
}

\author{
SALLY N DAVIES
}

A hungry shark beat us to it. We had just caught a fish, but when we pulled it in only the head was left. My husband Nicholas and I are sailing from Bali to Cocos Keeling Islands and on across the Indian Ocean. A mere dot on most atlases, the Cocos atoll is an important milestone, as after there we should be safely out of this area with its rapidly approaching hurricane season. The sun glares down from directly overhead and the trade winds push us westwards through the lazy ocean swell.

In 1979 we left England in Liemba, our 35 foot yacht, to cross the Atlantic and sail via the Panama Canal to California where Nick had arranged a research post. As our time in San Diego drew to a close we considered sailing across the Pacific. Who could resist the lure of the south seas when poised on the brink? Not us, so we duly set off to navigate that magnificent ocean and to reach Australia, half way round the world. So now we are bringing our stalwart little boat home, our goal, to sail her back up the River Lymington whence she came.

As doctors in the close knit circle of "yachties" that we were to meet on our travels we were inevitably asked for medical advice. Much of our time was in the tropics and in regions with unfamiliar and dangerous creatures, so we had to be ready to tackle such problems as stinging coral, sea snake bites, and poisonous fish. A common condition was the indolent tropical ulcer, that festering sore that starts from the most minor trauma. Occupational hazards of sailing were another aspect: burns from the endless battle with the galley stove when the sea and sky are constantly changing places, mangled fingers that got trapped between rope and winch when the strain took up suddenly in a squall, the ubiquitous fungal infestation that loves salty skin (fresh water is a precious commodity for long distance sailors).

There were a few more memorable events when our skills were

Department of Virology, London Hospital Medical College, London E1 2AD SALLY N DAVIES, MB, BS, registrar

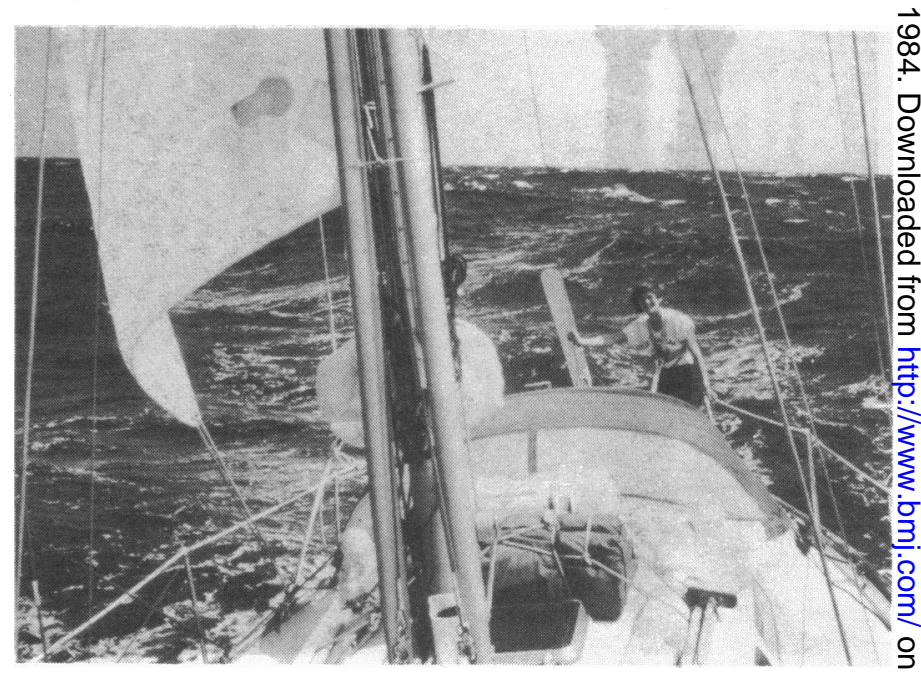

Rough weather crossing the Caribbean.

needed. While sailing up the lonely Mexican coast, we met a young American with abdominal pain. The only doctor in the isolated N fishing village nearby had seen, but not examined him, prescribed $\sigma$ antacids and chloramphenicol, charged $\$ 100$, and sent him back to his home built trimaran. By the time that we saw him he was most unwell with generalised peritonitis and from the history we diagnosed a ruptured appendix. Luckily, another boat had a radio 7 and we were able to contact a flying ambulance in San Diego. A $\overline{0}$ small plane flew the 1500 miles to land in a field hastily cleared of scraggy cows by the locals. On arrival in the States, the leaking appendix was removed and he made a good recovery.

While navigating a tricky reef passage, an orthopaedic surgeon friend of ours hooked a four foot barracuda. All other eyes were on the jagged coral heads just below the surface, so he tried to land it alone. The angry fish voiced its objections by sinking vicious teeth $\frac{0}{\partial}$ 
into his hand. The damage was a nasty gash through the proximal interphalangeal joint of his right index finger. Despite being right handed, as a surgeon he realised that only he was capable of such a delicate repair. He gave himself a ring block and put in the stitches, but the reverse left handed knots defeated him and a little help from us was required. The fish got away so we were even deprived of the pleasure of eating it.

Once we were asked to see a tourist who had fallen off his windsurfer on to a reef and cut his foot badly on the coral. Stitches were needed and, as the only alternative medical help was on the next island a few hours' boat trip away, we set to work. Our surgery was the beach, his bed a hammock slung between two palm trees, the anaesthetic a rum punch, and the instrument table a palm frond on the white sand. A rather novel setting for a casualty.

Occasionally, the tables were reversed. In Bora-Bora, that enticing Bali Hai of the South Pacific, I lost a filling. The island had no dentist, but to my delight a yacht anchored in the same bay was owned by a retired American dentist. He had wisely equipped his

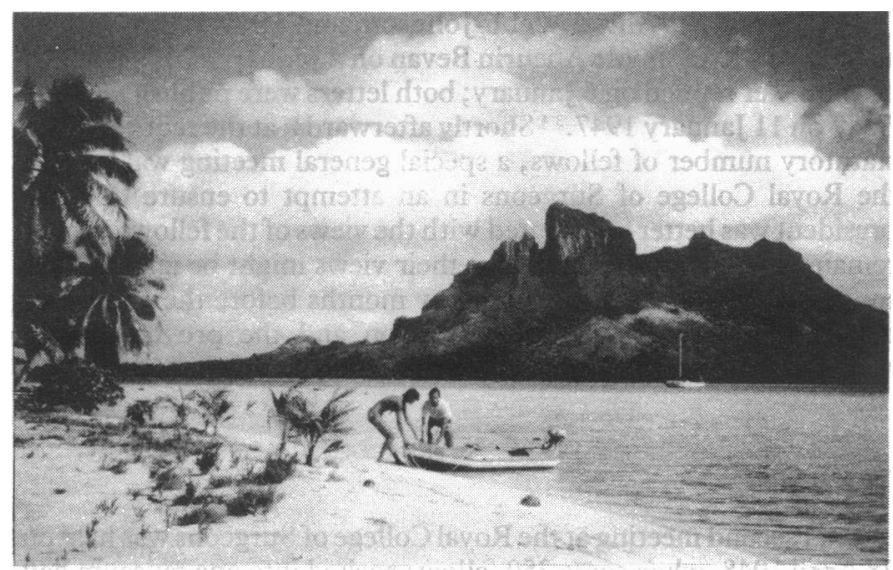

Landing on an uninhabited islet in Bora-Bora, French Polynesia.

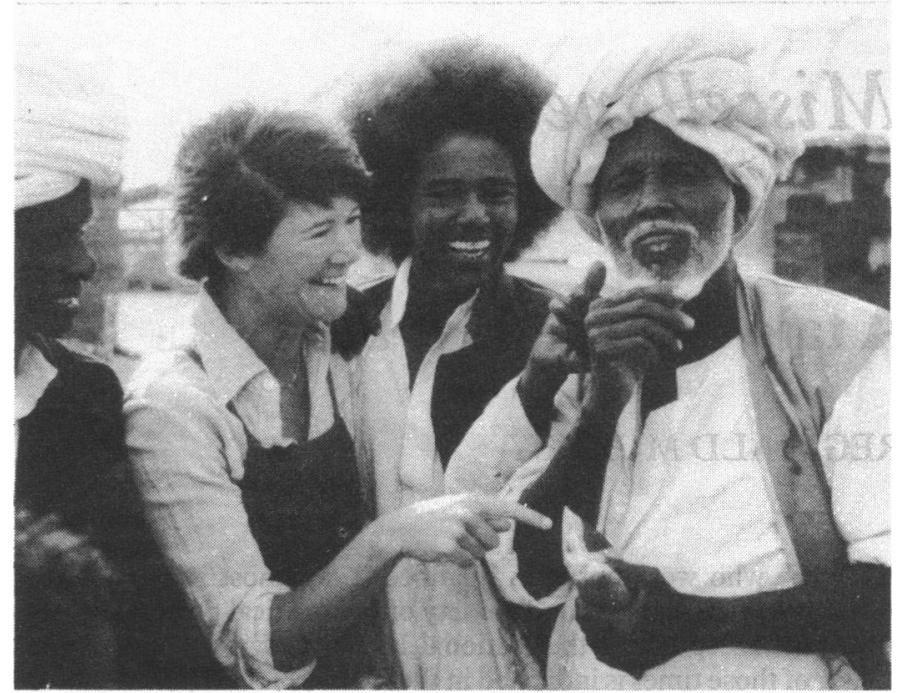

Trying to explain how to cook kidney beans to the Arabs of the northern Sudan.

boat as a floating surgery with a full range of dental instruments including an electric drill and a generator to run it. A light was all that he lacked, but his wife stood behind him, shining a torch over his shoulder into my mouth while he plugged the painful cavity.

What of the voyage? We have vivid memories of the joys of making landfalls after many weeks at sea, the different cultures that we discovered, and the thrill of trade wind sailing. But also etched in our minds are the storms we fought, the whales we hit, and being shot at by guerillas in Grenada. We feel privileged to have shared such a breadth of life. Still there is a price to pay. To take four years out of competitive medicine is a hard decision and a conflict that we both fought with while watching from afar as our friends' careers leapt ahead. But to take four years out of a lifetime is not so long, and we hope that the richness of experience gained will stand us in good stead for the difficulties of returning to a conventional world.

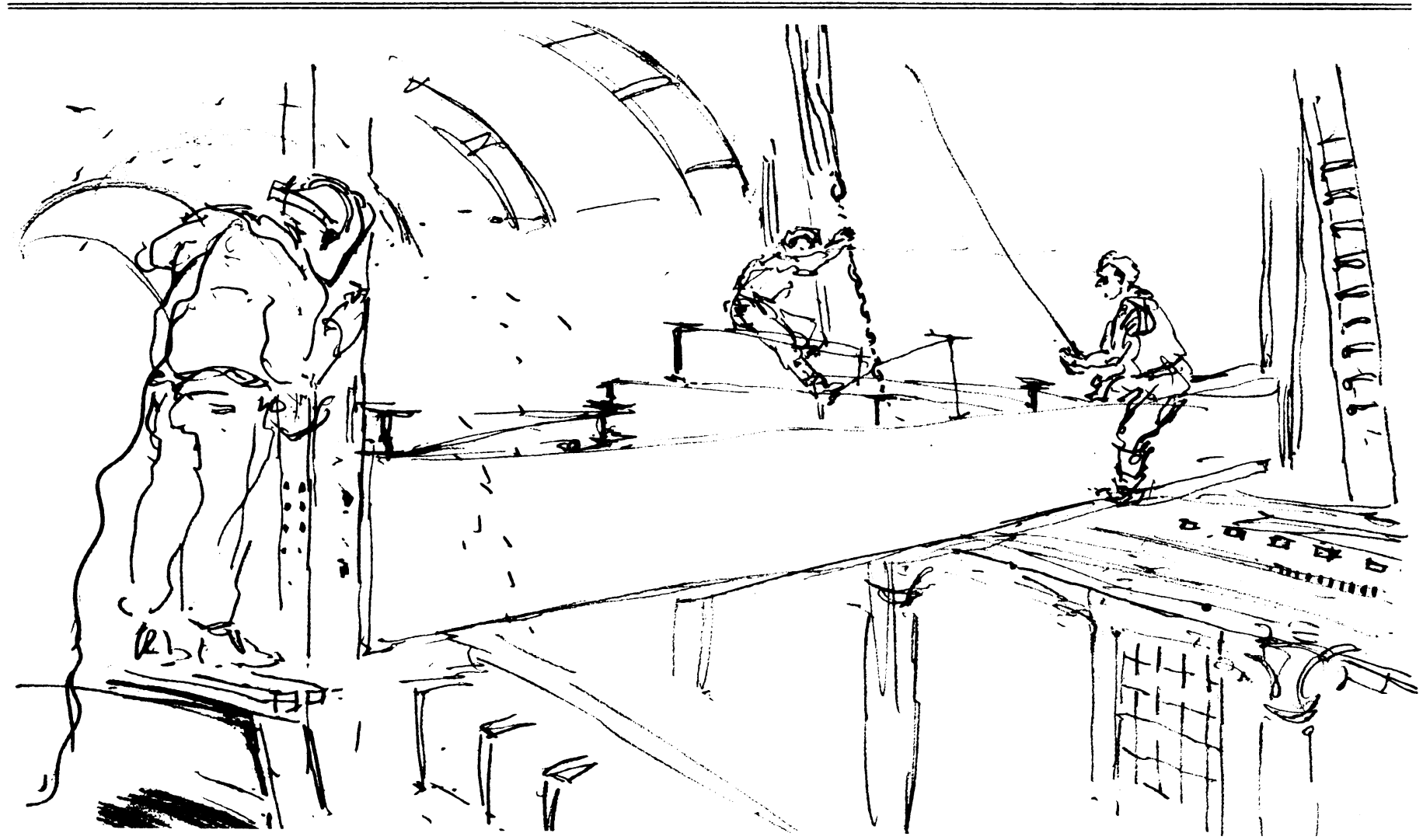

